\title{
REGIONAL SCIENCE AND APPLIED DEMOGRAPHY: EVER THE TWAIN SHOULD MEET
}

\author{
William J. Serow*
}

Regional science and demography (particularly the "applied" side of demography, a distinction I'll elaborate below) are disciplines which seem to me to have much in common. By their nature and evolution, both are "interdisciplinary" in the sense that the term is usually employed, but tend to be associated in the main, rightly or wrongly, with one of the "traditional" social science disciplines-economics most probably in the case of regional science and sociology most probably in the case of demography. As an aside, I might mention that historically and indeed even now in many parts of the world other than North America, demography is more generally associated with economics than with sociology. While the conventional association may be inaccurate for the many geographers, sociologists and other social scientists who consider themselves regional scientists and equally inaccurate for the many economists, geographers and other social scientists who consider themselves demographers, this association regrettably remains fixed, particularly in the mind of those individuals viewing one or the other fields of inquiry from some distance.

Apart from what I fear may appear to be academic schizophrenia, there are, of course, more significant interstices between regional science and applied demography in addition to their status as "stepchildren" to sometimes indifferent parent disciplines. Paramount among these interstices and, indeed, serving as the basis for these remarks, is the concentration within each discipline on the application of basically empirical methods of analysis toward the solution of real world, or practical problems.

At this junction, I'd like to return to the con-

*Florida State University, Tallahassee, The Presidential Address given to the annual meeting of the Southern Regional Science Association, Charleston, S.C., April $15,1983$. cept of applied demography. Demography, in its broadest sense encompasses all scientific study of human populations. Although demography as a discipline has never been particularly strong in abstract theory (borrowing instead its hypotheses on the determinants and consequences of human demographic behavior from sociology, economics, geography, and other disciplines), the past five years or so have seen a heightened interest in the importance of demographic variables in areas far removed from the ivory towers purportedly inhabited by academicians. More specifically, decision makers in both the private and public sectors have increasingly come to ask questions such as: What is the age and income distribution of our hospital service area now? Will these distributions change enough in the next ten years to plan on adding a new wing? What will the impact on the size and composition of our city's population be if we enact this new zoning ordinance? In short, and to use a term of which I am not particularly enamored, what are the "demographics" of the situation?

Clearly, I do not intend to advance the argument that all areas of demographic inquiry and all tools of demographic research are particularly useful for the average regional scientist on the street. In fact, I am reminded in this context of the occasion a few years ago when I was asked to review a book in family planning in Thailand for a regional science journal. I would guess that I spent more time trying to think of some plausible way I could say something of interest about this book to the self same regional-scientist-in-the-street than I did actually reading the book or writing the review.

While I doubt there exists any universally accepted definition of applied demography, let me suggest that it would at the least include the following skills: a) knowledge of techniques for estimation and projections of population and demographic parameters; b) the ability to point 
the nature and significance of the trends emergent from the nature and estimates and projections; and c) a thorough understanding of those sources of data, both conventional and unconventional, that may be employed in the other two activities. While it is difficult to really acquire the last mentioned of these in any manner other than learning by doing, I would suggest that the proverbial tool kit of our prototypical regional scientist would be much enhanced by acquiring the first two skills. I would venture to guess that in most cases, regional scientists would have some familiarity with all of these skills, but that this familiarity, especially in the first two cases, would be of the ad hoc variety. While this can lead to useful and appropriate conclusions in a particular setting, I would argue that the accumulation of such experiences becomes too idiosyncratic to be very generalizable.

Yet, I would also argue that the formal and informal training embodied in most regional scientists affords us a unique opportunity to learn from and to contribute to applied demography. Let me take a case to point. What might be called a purely demographic approach to population would involve a cohort-component technique whereby age-specific rates for each of the three demographic processes-fertility, mortality and migration-are applied to socalled populations at risk to produce the age distribution of population which would exist at some future point in time if the set of rates assumed for the demographic processes actually came to pass. Too often, due to convenience, lack of data, ignorance, sloth or wishful thinking, these rates are taken to be identical to those recorded at the time of the most recent census or derived over the most recent intercensal period.

So far, so good. I have quite deliberately tried to portray this purely demographic approach as being as mechanical as possible; I do so because all too often it is precisely and only thatmechanical. It seems to me that we regional scientists can contribute greatly toward the improvement of the assumption-making process, especially regarding assumptions about migration behavior. The focus on migration seems fitting for two reasons: first, there are numerous examples throughout the regional science literature dealing with models of the migration process, particularly those dealing with specific place to plane flows or the inter- play of economic (e.g., labor force activity) and demographic (e.g., age) variables in the determination of in and out migration rates. Second, at the subnational level, where I perceive most work in both regional science and applied demography to be directed, migration has emerged as the principal determinant of differential population growth rates and, given likely levels of future fertility, will continue to be so into the foreseeable future.

Unfortunately, while the contributions in this field of inquiry by persons professing some allegiance to regional science have been of enormous importance, these contributions are too often unknown by persons, professing some allegiance to demography. How can we explain the ignorance? Simply, that the contributions mentioned will appear in the Review of Regional Studies, the Annals of Regional Science, The International Regional Science Review, the Journal of Regional Science, and so on, rather than in Demography, the American Sociological Review, or Social Forces.

Clearly then, applied demographers could profit from the work of regional scientists in developing analytical population projection models where, for example, rates of migration are functionally related to projected changes in the demand for labor and/or the composition of this demand. Presumably, such models would be preferable and more accurate than the blatant fiction that one can mindlessly extrapolate from the past to arrive at the future.

Lest we become too self-satisfied, I must suggest that the indictment I have just issued to my colleagues in applied demography, especially those who arrive in applied demography from a strictly sociological background, can also be issued to my colleagues in regional science. Just as demographers are frequently blind to non-demographic material (in terms of the nature of the publication), so too are regional scientists blind to material not appearing in regional science, applied economics and perhaps geography oriented publications. All too often, one encounters otherwise sophisticated regional econometric models where population size is totally exogenous or is treated as a simple aggregate which responds, in totality, to forecast economic change. Such models ignore completely the age (and possibly other) compositional aspects of any population which, apart from any demand based considerations, will have a decided impact on the future course 
of that population.

I certainly do not wish to create the impression that this one quite narrow area of congruent interests-the migration component of population projection-is the only possible linkage between regional science and applied demography. One could argue, for example, that mortality analyses focusing on multiple decrement life tables linking cause of death with labor force participation and occupation/ industry patterns provides extremely important input to environmentally focused regional analyses. One could also argue, again for example, that the fertility behavior of the recent past directly impacts the size and composition of a regional economy's labor force and in the ability of that economy to absorb differing volumes and structure of potential new industry.

In a nutshell, I don't mean to recommend that all members of the Southern Regional Science Association should immediately purchase and study demographic manuals, foresake their memberships in SRSA to join the Southern Regional Demographic Group (although some of us do belong to both!) and hang up their shin- gle as applied regional demographic scientists. For one thing, demographic work would be tangential to the work of many regional scientists. For another, I am not sure whether I would need so much additional competition! I do believe, however, that the ability of most regional scientists to undertake their own fundamentally applied work, no matter what the particular application, would be enhanced by some greater familiarity with demographic principles and techniques. Similarly, I think the ability of most applied demographers to undertake their own fundamentally applied work no matter what the particular application, would be enhanced by some greater familiarity with regional science principles and techniques.

In brief, I find myself a reasonably staunch adherent to a pair of extremely complementary disciplines which have a great deal to share with each other but which, to my perception, almost totally ignore each other. Knowledge of demography may well promote better regional science just as knowledge of regional science may well promote better demography. 